\title{
Effect of Garlic (Allium Sativum) on Blood Glucose Level in Type 2 Diabetes Mellitus Patients Treated with Metformin
}

\author{
Md. Shefat Jahan Shoshi ${ }^{1}$, Abu Syed Md. Mosaddek ${ }^{2}$, Hasina Akter ${ }^{3}$ \\ ${ }^{1 .}$ Dr. Md. Shefat Jahan, Assistant Professor, Department of Pharmacology, \\ International Medical College, Gushulia Sataish, Tongi Gazipur. \\ 2. Dr. Abu Syed Md. Mosaddek, Professor \& Head Department of Pharmacology, \\ Uttara Adhunik Medical College, Dhaka. \\ ${ }^{3 .}$ Dr. Hasina Akter, Assistant Professor, Department of Physiology, International Medical College, \\ Gushulia Sataish, Tongi Gazipur.
}

\begin{abstract}
Background: Diabetes mellitus is a heterogeneous group of metabolic disorders with microvascular and macrovascular complications which are the major causes of morbidity and mortality in diabetic patients. Anti-diabetic drugs are available in modern medicine but prolong use of these drugs may produce some side effects. Garlic due to some of its active component can improve glycaemic status. Objective: To observe the effect of garlic (Allium sativum) in patients of type 2 diabetes mellitus with obesity. Method: This prospective interventional study was carried out in the Department of Pharmacology, Sir Salimullah Medical College (SSMC), Dhaka from July 2014 to June 2015. Total number of sixty (60) type 2 diabetes mellitus with obesity subjects of both sexes with age range 40 to 60 years was included in this study. They were selected on the basis of inclusion and exclusion criteria from Out Patient Department of Bangladesh Institute of Rehabilitation of Diabetic, Endocrine and Metabolic disorder (BIRDEM) hospital, Dhaka. The subjects were divided into two groups by simple random sampling. One was group A and another was group B. The subjects (30) of group A were supplemented only metformin at a dose of (1000mg) per day. The subjects (30) of group $B$ were supplemented metformin at a dose of (1000mg) and garlic in capsule form at a dose of (500mg) per day. They were studied two times i,e. on day-1( $1^{\text {st }}$ day of metformin treated, Group $\left.A_{1}\right)$, on 12 weeks (After 12 weeks of metformin treated, Group $A_{2}$ ), on day-1(Before supplementation of garlic, Group $\left.B_{1}\right)$ and on 12 weeks (After 12 weeks supplementation of garlic and metformin, Group $B_{2}$ ). Fasting blood glucose level and postprandial blood glucose level of all subjects were measured by glucose oxidize method. Blood HbAlc level of all participants was measured by immunoassay method. The statistical analysis was done by using paired and unpaired sample ' $t$ ' test. Results: In this study, the mean FBG and PPBG levels were decreased non significantly $(p>0.05)$ in after 12 weeks treated of metformin in comparison to $1^{\text {st }}$ day of metformin treated. Again, the mean FBG and $P P B G$ levels were decreased significantly in after 12 weeks supplementation of metformin and garlic in compared to before supplementation of garlic $(p<0.001)$ and after 12 weeks supplementation of metformin ( $p<0.05)$. Again, Blood HbAlc level was decreased non significantly $(p>0.05)$ after 12 weeks treated of metformin and metformin and garlic supplementation in compared to $1^{\text {st }}$ day of metformin treated and before supplementation of garlic. Conclusion: The present study revealed that, garlic (Allium sativum) has significant effect on improvement of glycaemic status.
\end{abstract}

Keywords: Diabetes mellitus, garlic, FBG, PPBG and HbAlc.

\section{INTRODUCTION}

Diabetes mellitus is as defined as chronic or persistent hyperglycaemia, due to deficiency of insulin secretion or of insulin action, or both ${ }^{1}$. Diabetes mellitus is known as the most growing metabolic disease that characterized by altered carbohydrate, lipid and protein metabolism ${ }^{2}$. According to World Health Organization (WHO) the prevalence of diabetes mellitus in the global population is approximately $9 \%$, of which $90 \%$ is type 2 diabetes mellitus. However, the prevalence of diabetes mellitus in Bangladesh is approximately $10 \%$. The incidence of diabetes mellitus are increasing day by day which can be increased from 150 million to 300 million by the year $2025^{3}$. Characteristic symptoms of diabetes mellitus are thirst, dry mouth, polydipsia, polyuria, tiredness, fatigue, blurring of vision, and weight loss; in its most severe form, symptoms are ketoacidosis, nonketotic hyper- 
osmolar coma, and death ${ }^{4}$. The principle laboratory findings of type 2 diabetes mellitus is hyperglycemia, either fasting blood glucose (FBG) level $126 \mathrm{mg} / \mathrm{dL}$ or glycosylated hemoglobin $\left(\mathrm{HbA}_{1} \mathrm{c}\right) 6.5 \%{ }^{1}$.

Type 2 diabetes mellitus is a chronic disorder characterized by chronic hyperglycemia, with long term macrovascular and microvascular complication ${ }^{5}$. According to World Health Organization type 2 diabetes constitutes about $85 \%$ to $95 \%$ of all diabetes. This increasing trend of type 2 diabetes is associated rapidly changing lifestyle such as increasing urbanization, dietary changes, reduced physical activity along with population aging ${ }^{3}$. Type 2 diabetes mellitus most commonly occur after 40 years ${ }^{4}$.

The general consensus is that the main treatment of type 2 diabetes is lifestyle management, like exercise and weight reduction. Pharmacological agents, including sulfonylureas, biguanides, alphaglucosidase inhibitors, thiazolidinediones and meglitinide, are also used; however, long-term complications of type 2 diabetes mellitus are unaltered with these agents ${ }^{6}$. Metformin is currently being used in type 2 diabetes as the first-choice oral agent, along with appropriate diet control and modification of lifestyle ${ }^{7}$. Metformin acts primarily by reducing the hepatic glucose output and improving insulin sensitivity in the liver and muscle ${ }^{8}$. Metformin has pleiotropic vascular effects that act on endothelial imbalance, probably increasing nitric oxide bioavailability, decreasing atheroma plaque growth, improving the atherogenic lipid profile, and inhibiting lipid incorporation into vessel walls, thereby inhibiting vascular smooth muscle cell proliferation ${ }^{9}$. The American Diabetic Association has recommended metformin as a first-line agent for the treatment of type 2 diabetes, as metformin helps in weight loss and lowers fasting plasma insulin concentrations, total and lowdensity lipoprotein cholesterol, and free fatty acids ${ }^{10}$. Metformin is useful in the prevention of type 2 diabetes; the landmark Diabetes Prevention Program concluded that metformin is efficacious in preventing the new onset of type 2 diabetes in middle-aged, obese person with impaired glucose tolerance and fasting hyperglycemia ${ }^{11}$. It is interesting that metformin did not prevent diabetes mellitus in older, leaner prediabetic ${ }^{7}$. However, long-term complications are not altered with metformin therapy. Previous studies have shown mixed results of metformin therapy on CRP, but the studies of non-diabetic patients have reported greater inhibitory effects on CRP than the studies of diabetics. Thus, the effect of metformin therapy on CRP needs to be established in type 2 diabetic patients ${ }^{12}$. However, epidemiologic studies suggest that metformin use may dramatically reduce the risk of some cancers 7 . The World Health Organization Expert Committee on diabetes has recommended that traditional medicinal herbs can be further investigated for the treatment of diabetes mellitus. The most commonly used medicinal herbs: Allium sativum (garlic), Ginseng species, Momordica charantia (bitter melon), Trigonella foenum-graecum (fenugreek) and A. cepa (onion) ${ }^{3}$.

Allium sativum, commonly known as garlic is widely used around the world with a history of human use of over 7,000 years for culinary and medicinal purpose ${ }^{13,14}$. Recently, garlic has used in the form of garlic oil, garlic powder and pills are widely used for certain therapeutic purposes ${ }^{15}$. Garlic has a reputation in particular because of its widespread health use around the world as a dietary as well as therapeutic supplement ${ }^{16}$. Garlic contains a variety of effective compounds, such as allicin, a sulfurcontaining compound that exhibits Hypocholesterolemic effect ${ }^{17}$. Antioxidant effect ${ }^{18}$. Hypotensive, anticoagulant and antithrombotic effect ${ }^{19}$. Garlic exhibits a wide range of properties including Immunomodulatory and Hepatoprotective effect ${ }^{20}$. Garlic extracts are believed to possess beneficial effects for the prevention of cardiovascular diseases ${ }^{21}$. Garlic helps to maintain electrolytes balance especially sodium and potassium ${ }^{22}$.

It has been observed that, consuming $10 \mathrm{~g}$ of raw garlic per day in two meals for six weeks can reduce blood glucose and $\mathrm{HbA}_{1} \mathrm{c}$ level in patients with diabetes mellitus ${ }^{23}$. Some other researchers showed that, daily $40 \mathrm{mg}$ garlic consumption may improve blood HDL-cholesterol levels ${ }^{24}$.

\section{MethodS}

This prospective interventional study was carried out in the Department of Pharmacology, Sir Salimullah Medical College (SSMC), Dhaka between $1^{\text {st }}$ July 2014 and $30^{\text {th }}$ June 2015. According to selection criteria all the study subjects were selected from Out Patient Department of Bangladesh Institute of Rehabilitation of Diabetic, Endocrine and Metabolic disorder (BIRDEM) hospital, Dhaka. After proper counseling, the aim, objectives, risk and the procedure of the study were explained in details to the subjects. Only positive respondents were recruited as research participants and were 
allowed to withdraw themselves from the study even after participation whenever they like. Ethical permission was taken from the Institutional Ethics Committee (IEC) of Sir Salimullah Medical College.The subjects were divided into two groups by simple random sampling. One was group A and another was group B. The subjects (30) of group A were supplemented only metformin at a dose of $(1000 \mathrm{mg})$ per day. The subjects (30) of group B were supplemented metformin at a dose of $(1000 \mathrm{mg})$ and garlic in capsule form at a dose of $(500 \mathrm{mg})$ per day. They were studied two times i,e. on day- $1\left(1^{\text {st }}\right.$ day of metformin treated, Group $A_{1}$ ), on 12 weeks (After 12 weeks of metformin treated, Group $A_{2}$ ), on day-1(Before supplementation of garlic , Group $\mathrm{B}_{1}$ ) and on 12 weeks (After 12 weeks supplementation of garlic and metformin, Group $\mathrm{B}_{2}$ ). Subjects having type-1 diabetes mellitus, hypertension, heart disease, kidney disease, liver disease, thyroid disease, infectious disease etc were excluded from the study. Informed written consent was taken from each subject. Then their general information and data were collected and all the information were recorded in a prefixed questionnaire.

With all aseptic precautions, five (5) $\mathrm{ml}$ of venous blood was drawn from median cubital vein by sterile disposable syringe. To assess their glycaemic status FBG and PPBG level were measured by glucose oxidize method and blood HbA1c level measured by immunoassay method in the laboratory of Department of Biochemistry of BSMMU, Dhaka. These parameters were studied 2 times among all subjects, i. e. on day-1 and after 12 weeks. Data were analyzed by Paired sample ' $t$ ' test as applicable for statistical analysis. P value $<0.05$ was taken as level of significance.

\section{Garlic supplementation}

All the subjects of group B of this study were supplemented with garlic capsule containing $(250 \mathrm{mg})$ garlic two times daily for 12 weeks ${ }^{13}$. These subjects were taken from Out Patients department of Bangladesh Institute of Rehabilitation of Diabetic, Endocrine and Metabolic disorder (BIRDEM) hospital, Dhaka.

\section{Results}

In this study, FBG, PPBG and HbA1c levels were non significantly decreased after 12 weeks treated of metformin in comparison to $1^{\text {st }}$ day of metformin treated. Again, the mean FBG and PPBG levels were decreased significantly but HbA1c level decreased non significantly after 12 weeks supplementation of metformin and garlic in compared to before supplementation of garlic and after 12 weeks treated of metformin.

Table I: Age, FBG, PPBG and HbAlc level in different groups ( $n=60)$

\begin{tabular}{|c|c|c|}
\hline Parameters & $\begin{array}{c}\text { Group } \mathbf{A}_{\mathbf{1}} \\
(\mathbf{n = 3 0})\end{array}$ & $\begin{array}{c}\text { Group } \mathbf{B}_{\mathbf{1}} \\
(\mathbf{n}=\mathbf{3 0})\end{array}$ \\
\hline Age (years) & $48.23 \pm 4.59$ & $47.83 \pm 4.71$ \\
\hline FBG (mmol/l) & $8.52 \pm 0.29$ & $8.49 \pm 0.24$ \\
\hline PPBG (mmol/l) & $10.69 \pm 0.28$ & $10.46 \pm 0.24$ \\
\hline HbA1c (\%) & $7.49 \pm 0.23$ & $7.44 \pm 0.12$ \\
\hline
\end{tabular}

Data are expressed as mean \pm SD. For statistical analysis, Independent sample 't' test was done for comparison between the groups. Figures in parentheses indicate ranges. Group $\mathbf{A}_{1}$ : Metformin treated (on day-1); Group $\mathbf{B}_{1}$ : Before supplementation of garlic (on day-1); $\mathrm{n}=$ total number of the subject

Table II: $F B G, P P B G$ and HbAlc level in different groups $(n=60)$

\begin{tabular}{|c|c|c|c|}
\hline Groups & $\begin{array}{c}\text { FBG } \\
(\mathbf{m g} / \mathbf{d l})\end{array}$ & $\begin{array}{c}\text { PPBG } \\
(\mathbf{m g} / \mathbf{d l})\end{array}$ & $\begin{array}{c}\text { HbA1C } \\
(\mathbf{\%})\end{array}$ \\
\hline $\mathbf{A}_{\mathbf{1}}(\mathbf{n}=\mathbf{3 0})$ & $8.52 \pm 0.29$ & $10.69 \pm 0.28$ & $7.49 \pm 0.23$ \\
& $(8.05-9.10)$ & $(8.6-11.4)$ & $(7.20-1.33)$ \\
\hline $\mathbf{A}_{\mathbf{2}}(\mathbf{n}=\mathbf{3 0})$ & $8.48 \pm 0.24$ & $9.45 \pm 0.26$ & $7.42 \pm 0.22$ \\
& $(7.48-8.35)$ & $(8.23-9.50)$ & $(7.20-7.90)$ \\
\hline $\mathbf{B}_{\mathbf{1}}(\mathbf{n}=\mathbf{3 0})$ & $8.49 \pm 0.24$ & $10.46 \pm 0.24$ & $7.44 \pm 0.12$ \\
& $(8.20-9.50)$ & $(8.55-11.35)$ & $(7.25-7.78)$ \\
\hline $\mathbf{B}_{\mathbf{2}}(\mathbf{n}=\mathbf{3 0})$ & $6.30 \pm 0.18$ & $7.55 \pm 0.21$ & $7.27 \pm 0.05$ \\
& $(5.42-7.23)$ & $(6.3-8.78)$ & $(7.20-7.35)$ \\
\hline \multicolumn{3}{|c|}{ Statistical analysis } & (p value) \\
\hline \multicolumn{4}{|c|}{} \\
\hline
\end{tabular}


Md. Shefat Jahan Shoshi et al.

\begin{tabular}{|c|c|c|c|}
\hline \hline $\mathbf{A}_{\mathbf{2}} \mathbf{v S ~ \mathbf { B } _ { 2 }}$ & $.05^{*}$ & $.01^{* *}$ & $.000^{* * *}$ \\
\hline $\mathbf{B}_{\mathbf{1}} \mathbf{v S ~ \mathbf { B } _ { 2 }}$ & $.000^{* * *}$ & $.000^{* * *}$ & $.569^{\mathrm{ns}}$ \\
\hline
\end{tabular}

Data are expressed as Mean \pm SD. For statistical analysis, paired-samples t test within the group were performed. Figures in parentheses indicate ranges.

Group $\mathbf{A}_{1}$ : Metformin treated (on day-1).

Group $\mathbf{A}_{2}$ : After 12 weeks treated of Metformin
Group $\mathbf{B}_{1}$ : Before supplementation of garlic (on day-1).

Group $\mathbf{B}_{2}$ : After 12 weeks supplementation of Metformin plus garlic.

$*=$ Significant at $\mathrm{p}<0.05 ; * *=$ Significant at $\mathrm{p}<0.01 ; * * *=$ Significant at $\mathrm{p}<0.001$; $\mathrm{ns}=$ Non significant $\mathrm{n}=$ total number of the subjects

\section{DISCUSSION}

Anti-diabetic medications have significant side effects that are not familiar with patients, have limited effectiveness or lack evidence of impacting the course of the disease. An increasing interest in herbal and complementary medicine has led to a search for effective natural therapies that have significant effects on blood glucose level. Herbal treatment can be a safe and cost effective way to combat diabetes mellitus.

The present study has been undertaken to observe the effect of garlic (Allium sativum) on type 2 diabetes mellitus with obesity subjects. For this, the levels of fasting blood glucose (FBG), postprandial blood glucose (PPBG) and $\mathrm{HbA}_{1} \mathrm{c}$ were measured to assess their blood glucose level status. In this study, total 60 type 2 diabetes mellitus with obesity subjects of both sex, age ranged from 40 to 60 years were taken. All the subjects were divided randomly into two groups. Each group consists of 30 subjects. Group A was given only metformin tablets $(500 \mathrm{mg})$ two times per day and Group B was given garlic capsule $(250 \mathrm{mg})$ two times along with metformin tablets $(500 \mathrm{mg})$ two times per day for 12 weeks. All the subjects of both groups were studied 2 times, on day- $1\left(1^{\text {st }}\right.$ day of metformin treated, Group $A_{1}$ ), on 12 weeks (After 12 weeks treated of metformin, Group $A_{2}$ ), on day1(Before supplementation of garlic, Group $B_{1}$ ) and on 12 weeks (After 12 weeks supplementation of garlic and metformin, Group $\mathrm{B}_{2}$ ). In this study, the mean FBS, PPBG, blood $\mathrm{HbA}_{1} \mathrm{c}$ and serum lipid profile levels were almost similar and the differences were not statistically significant between the group A and group B on day-1. The dose of garlic and methodology were followed from Kumar et al. (2013).

\section{Fasting blood glucose (FBG) level}

In this study, FBG level was decreased non significantly ( $p>0.05)$ after 12 weeks treated of metformin after in comparison to that of metformin treated (on day-1). Again, FBG level was decreased significantly $(\mathrm{p}<0.001)$ after 12 weeks supplementation of metformin plus garlic compared to that of before supplementation of garlic (on day-1). Moreover, FBG level was decreased significantly $(\mathrm{p}<0.05)$ after 12 weeks supplementation of metformin plus garlic compared to that of after 12 weeks treated of metformin. This finding is consistent with that of other investigator (Kumar et al. 2013). In the study garlic capsule was give for twelve weeks at $(500 \mathrm{mg})$ doses daily in type 2 diabetes mellitus with obesity subjects. This finding is similar with that of other investigators (Dehghani et al. 2013 and Mahmoodi et al. 2013). This could be due to garlic increased insulin secretion and sensitivity.

\section{Postprandial blood glucose (PPBG) level}

In this study, PPBG level was decreased non significantly ( $p>0.05$ ) after 12 weeks treated of metformin in comparison to that of metformin treated (on day-1). Again, PPBG level decreased significantly $(p<0.001)$ after 12 weeks supplementation of metformin plus garlic compared to that of before supplementation of garlic (on day-1). Moreover, PPBG level was decreased significantly $(\mathrm{p}<0.01)$ after 12 weeks supplementation of metformin plus garlic compared to that of after 12 weeks treated of metformin. This finding is similar with that of some other investigator (Mannucci et al. 2012). In the study, garlic capsule was given for eighteen weeks at $(500 \mathrm{mg})$ doses daily in type 2 diabetes mellitus with obesity subjects taking glibenclamide. This finding is equivocal with other investigators (Assaduzzaman et al. 2010). 


\section{Blood $\mathrm{HbA}_{1} \mathrm{c}$ level}

In the study, Blood $\mathrm{HbA}_{1} \mathrm{c}$ level was decreased non significantly ( $\left.\mathrm{p}>0.05\right)$ after 12 weeks treated of metformin in comparison to that of metformin treated (on day-1). Again, Blood $\mathrm{HbA}_{1} \mathrm{c}$ level was decreased non significantly ( $>0.05)$ after 12 weeks supplementation of metformin plus garlic compared to that of before supplementation of garlic (on day-1). Moreover, Blood $\mathrm{HbA}_{1} \mathrm{c}$ level was decreased significantly $(\mathrm{p}<0.01)$ after 12 weeks supplementation of metformin plus garlic compared to that of after 12 weeks treated of metformin. This finding is equivocal with that of some other investigators (Kumar et al. 2013 and Assaduzamman et al. 2010). Whereas, Stumvoll et al. (1995) found significant change of $\mathrm{HbA}_{1} \mathrm{c}$ level in type 2 diabetes mellitus subjects with garlic supplementation $(750 \mathrm{mg}$ ) per day for 18 weeks. It might be due to higher dose and long duration of their study period.

\section{Conclusion}

From this study, it can be concluded that, garlic (Allium sativum) has got significant effect on improvement of glycaemic status with lowering fasting blood glucose level and postprandial blood glucose level.

\section{REFERENCES}

[1] Pearson ER, McCrimmon RJ. Diabetes mellitus. In: Colledge NR, Walker BR, Ralston, SH. (eds.). Davidson's Principle and Practice of Medicine. $22^{\text {th }}$ ed. China. Churchil Livingstone Elsevier. 2014; pp. 809.

[2] Mutalik S, Sulochana B, Chetana M, Udupa N, Devi UP. Preliminary studies on acute and subacute toxicity of an antidiabetic herbal preparation, Dianex. Indian Journal of Experimental Biology, 2003 ; ( 41), pp. 316-320.

[3] World Health Organization experts committee on status report on diabetes mellitus. 2012 July; 10- 22.

[4] Field MJ, Burnett L, Sullivan DR, Stewart P. Clinical biochemistery and metabolism. In: Walker BR, Colledge NR, Ralston SH, Penman ID. (eds.). Davidson's Principle and Practice of Medicine. $22^{\text {th }}$ ed. China. Churchil Livingstone Elsevier. 2014; pp. 447-458.

[5] Kumar R, Chhatwal S, Arora S, Sharma S, Singh J, Singh N, Bhandari V, Khurana A. Antihyperglycemic, antihyperlipidemic, anti-inflammatory and adenosine deaminase-lowering effects of garlic in patients with type 2 diabetes mellitus with obesity. J. of Diabetes,

[6] Metabolic Syndrome and Obesity. 2013; (6), pp. 49-56.

[7] De. Fronzo, R.A. (1999) Pharmacologic therapy for type 2 diabetes mellitus. Ann Intern Med. 131(4), pp. 281-303.

[8] Matha S, Kennedy N. Pancreatic hormones \& Antidiabetic drugs. In: Katzung, B. G., Masters, S. B. and Trevor, A. J. (eds.). Basic \& Clinical Pharmacology. $12^{\text {th }}$ ed. India. Tata McGraw-Hill. 2012; pp. 757.

[9] Lima LM, Wiernsperger N, Aguiar KLG, Bouskela E. Short-term treatment with metformin improves the cardiovascular risk profile in first-degree relatives of subjects with type 2 diabetes mellitus who have a metabolic syndrome and normal glucose tolerance without changes in $\mathrm{C}$ reactive protein or fibrinogen. Clinics (Sao Paulo). 2009; 64(5), pp. 415-420.

[10] Bouskela E, Patel P, Wiernsperger N, Aguiar KLG. Short-term treatment with metformin improves the cardiovascular risk profile in first-degree relatives of subjects with type 2 diabetes mellitus who have a metabolic syndrome and normal glucose tolerance without changes in $\mathrm{C}$ reactive protein or fibrinogen. Clinics (Sao Paulo). 2009; 64(6), pp. 410-415.

[11] American Diabetes Association. Standards of medical care in diabetes - 2011. Diabetes Care. 2011. 34(1), pp. S11-S61.

[12] Haffner, S., Temprosa, M. and Crandall, J. (2005) Diabetes Prevention Program Research Group. Intensive lifestyle intervention or metformin on inflammation and coagulation in participants with impaired glucose tolerance. Diabetes. 54(5), pp.1566-1572.

[13] Caballero, A.E., Delgado, A., Aguilar-Salinas, C.A., Herrera, A.N., Castillo, J.L. and Cabaera, T. (2004) The differential effects of metformin on markers of endothelial activation and 
inflammation in subjects with impaired glucose tolerance: a placebo-controlled, randomized clinical trial. J Clin Endocrinol Metab. 89(8), pp. 3943-3948.

[14] Ensminger, A.H. (1994) Foods and Nutrition Encyclopedia. CRC Press. 1, pp. 750.

[15] Simonetti, G. and Schuler, S. (1990) Simon and Schuster's guide to Herbs and Spices. MiddleEast J. Sci. Res. pp. 75.

[16] Elkayam A, Mirelman E, Peleg M, Wilcheh T, Miron A, Rabinkov M, Henman O, Rosenthal T. The effects of allicin on weight in fructoseinduced hyperinsulinemic, hyperlipidemic, hypertensive rats. Am. J. Hypertension. 2003; (16), pp. 1053-1056.

[17] Gorinstein A, Harats D, Rabinkov A, Miron T, Mirelman D, Wilchek M. The antiatherogenic effect of allicin: possible mode of action. Pathobiology. 2006; (72), pp. 325-334.

[18] Khalid S, Al-Numair. Hypocholesteremic and Antioxidant Effects of Garlic (Allium sativum L.) Extract in Rats Fed High Cholesterol Diet. Pakistan J. of Nutrition. 2009; 8(2), pp. 161-166.

[19] Drucker A. Growing Garlic from True Seed. Garlic Analecta. 2014; ( 2), pp. 120-125.

[20] Vilela MAL, Alves PC, Akimoto AK., Pereira LC, Guimaraes NKMD, Grisolia CK. The effect of hydrogen peroxide induced oxidative stress on leukocytes depends on age and physical training in healthy human subjects carrying the same genotypes of antioxidant enzymes' gene polymorphisms. American J. of Human Biology, 2012; (22), pp. 807-812.

[21] Tanideh S, Badiei T. Hypocholesteremic and Antioxidant Effects of Garlic (Allium sativum L.) Extract in Rats Fed High Cholesterol Diet. Pakistan J. of Nutrition. 2009; 8(2), pp. 161-166.

[22] Block E. Garlic and others Alliums. The Lore and the Science. J. of Royal society of chemistry. 2010.

[23] Sumiyoshi, H. (1997) New pharmacological activities of garlic and its constituents (Review). Folia Pharmacological Japonica. 110 (1), pp. 93-97.

[24] Mahmoodi M, Hosseini ZSM, Hassanshahi GH, Toghroli MA, Khaksari M, Hajizadeh MR, Mirzajani E. The effects of consumption of raw garlic on serum lipid level, blood suger and a number of effective hormones on lipid and suger metabolism in hyperglycemic and/or hyperlipidemic indivisuals. J. of Advances in Biological Chemistry. 2011; (1), pp. 29-33. 